\section{Dr. Wiland, et al, reply}

\section{To the Editor:}

We thank Prof. Bannwarth for his insight into the potential influence of methotrexate (MTX) dosing in the PRIZE clinical trial ${ }^{1}$. The objective of the PRIZE study was to compare sustained remission rates after 39 weeks of reduced medication in patients with rheumatoid arthritis who had first achieved remission after 52 weeks' treatment with a combination of etanercept (ETN), $50 \mathrm{mg}$ subcutaneously (SC) once a week, and MTX, orally 10-25 mg once a week. The MTX dose was optimized for combination therapy with the standard dose of ETN, with induction of remission as the goal. The primary analysis was a comparison of sustained remission rates between patients switched to a reduced dose of ETN ( $25 \mathrm{mg}$, with the MTX dose and route of administration kept constant) versus patients switched to placebo. Serving as a standard therapy control, a third cohort discontinued ETN and continued MTX, again with the dose and route of administration kept constant. A secondary endpoint was comparison of the reduced-dose ETN and MTX combination (ETN/MTX) with standard oral MTX monotherapy. After 39 weeks of treatment, the remission rates in the ETN/MTX and placebo groups were $63 \%$ and $23 \%$, respectively $(\mathrm{p}<0.001$; pairwise comparison). The remission rate in the MTX monotherapy group was $40 \%(p<0.009 \text {; pairwise comparison with ETN/MTX })^{2}$.

Analysis of patient-reported outcomes (PRO) was described in our recent article and showed a similar pattern ${ }^{3}$. The placebo group showed worsening of PRO compared with the ETN/MTX group. The MTX group also showed greater worsening of PRO than the ETN/MTX group, but not as much as the placebo group. We agree with Prof. Bannwarth that we cannot exclude the possibility that switching to SC MTX rather than continuing oral MTX would have prevented or lessened PRO worsening in the MTX group. However, the study was designed to examine differences between reduced dose ETN/MTX therapy, oral MTX monotherapy, and placebo. The study design necessitated keeping the MTX route of administration constant throughout the study; thus the effect of different MTX regimens on sustained remission cannot be estimated.
PIOTR WILAND, MD, PhD, Professor, Head of Department, Department of Rheumatology and Internal Medicine, Wroclaw Medical University, Wroclaw, Poland; JEAN DUDLER, MD, Clinic of Rheumatology, HFR Fribourg, Hôpital Cantonal, Fribourg, Switzerland; DOUGLAS VEALE, MD, Professor, Dublin Academic Medical Centre, St. Vincent's University Hospital, Dublin, Ireland; HASAN TAHIR, MFSEM (UK), FRCP (UK), Professor, Barts Health National Health Service Trust, London, UK; RON PEDERSEN, MS, Pfizer Inc.; JACK BUKOWSKI, MD, PhD, Pfizer Inc.; BONNIE VLAHOS, MBA, BSN, RN, Pfizer Inc.; THERESA WILLIAMS, PA, MS, Pfizer Inc.; STEFANIE GAYLORD, BSN, RN, Pfizer Inc.; SAMEER KOTAK, MBA, MS, Pfizer Inc., Collegeville, Pennsylvania, USA.

Editorial/medical writing support was provided by Rina Vekaria Passmore of Engage Scientific Solutions and was funded by Pfizer. The PRIZE trial was sponsored by Pfizer. Dr. Wiland was a clinical trial investigator for the PRIZE study. Address correspondence to Prof. P. Wiland, Department of Rheumatology and Internal Medicine, Wroclaw Medical University, Borowska 213, 50-556 Wroclaw, Poland. E-mail: pwiland1@gmail.com

\section{REFERENCES}

1. Bannwarth B. Patients with rheumatoid arthritis in remission while receiving etanercept plus methotrexate therapy may require adjustment of dosing regimen when switched to methotrexate monotherapy. J Rheumatol 2017;44:259.

2. Emery P, Hammoudeh M, FitzGerald O, Combe B, Martin Mola E, Buch $\mathrm{MH}$, et al. Sustained remission with etanercept tapering in early rheumatoid arthritis. N Engl J Med 2014;371:1781-92.

3. Wiland P, Dudler J, Veale D, Tahir H, Pedersen R, Bukowski J, et al. The effect of reduced or withdrawn etanercept-methotrexate therapy on patient-reported outcomes in patients with early rheumatoid arthritis. J Rheumatol 2016;43:1268-77.

J Rheumatol 2017;44:2; doi:10.3899/jrheum.161405

Personal non-commercial use only. The Journal of Rheumatology Copyright (C) 2017. All rights reserved. 